\title{
Is doctor-patient relationship influenced by health online information?
}

\author{
Luciana Rodrigues Alves da Mota ${ }^{1}$ \\ Carolina Cavalcanti Gonçalves Ferreira ${ }^{1}$ \\ Henrique Augusto Alves da Costa Neto ${ }^{1}$ \\ Ana Rodrigues Falbo ${ }^{1}$ \\ Suélem de Barros Lorena ${ }^{1}$
}

1. Health College of Pernambuco, Pernambuco, Brasil

http://dx.doi.org/10.1590/1806-9282.64.08.692

\section{SUMMARY}

OBJECTIVES: TO analyse the opinions and attitudes reported by medical specialists regarding online health information and their interference in the doctor-patient relationship. Methods: A cross-sectional study developed between 2016 and 2017 in Recife-Pernambuco-Brazil, which used a questionnaire in person in a population of 183 specialists from the Instituto de Medicina Integral Prof. Fernando Figueira. The results were analysed through the Statistical Package for the Social Sciences. Obtained approval of the Ethics Committee under the voucher number 121004/2016. Results: In the opinion of $85.2 \%$ of physicians, online health information has both positive and negative impacts on the physician-patient relationship. Faced with a questioning patient who claims to have researched information on the internet, $98.9 \%$ of the physicians said they would try to explain the reasons for their diagnosis and treatment. 59\% already had a patient who modified the treatment recommended after seeing health information on the Internet. $73.8 \%$ agreed that online health information has positive effects for the general public, but $89.1 \%$ feel that most patients do not know which online health information is reliable.

CONCLUSION: The physicians surveyed view online health information in a positive way, but realize that it is necessary to be cautious as to their repercussions on the treatment of patients. There is concern about the accuracy of online health information, and it is incumbent upon the physician and health institutions to instruct patients about the sources of quality and that they are able to understand, as its known the patients have an active voice through the guarantee of the ethical principle of autonomy.

KEYWORDS: Internet. Physician-patient relations. Physician's role. Patient participation.

\section{INTRODUCTION}

The massive use of the internet and other media as sources of research to obtain information about health-disease processes has been causing impacts on the doctor-patient relationship. The Priestly Model of the doctor-patient relationship, as defined by Robert Veatch in 1972, which proposes complete submission of the patient to the physician, has been replaced by the Collegial Model, in which decision-making power is shared equally and there is no relation of superiority or inferiority. ${ }^{1}$

Some foreign studies have shown that over $40 \%$ of patients seek information online before undergoing a procedure or before consulting a physician. ${ }^{2,3}$ After consultation, many base their health decisions 
on information found online without discussing about this information with the healthcare professional. ${ }^{4,5}$ In this sense, the doctor is often not aware of the whirlwind of doubts and expectations that the patient presents. This mismatch of information may omit important details in the anamnesis, which has repercussions on the treatment and prognosis of the patient, generating mistrust between the two subjects in communication.

Often online health research among patients reflects the dissatisfaction and discontent that some patients have when they formally consult a medical professional. ${ }^{2}$ It is possible that this dislike expressed by many patients stems from the current fragmentation of medicine in specialized areas, so that today the doctor tends not to look at the patient as a subject that expresses desires, wants and expectations, but as a part of the whole. In this way, the biopsychosocial aspect of the disease is forgotten. ${ }^{6}$

Although online health and disease information is often enlightening, the patient may have multiple and different answers to his/her questions, since many of the sources present wrong information. In addition, the intellectual level of the patient is a factor that has an impact on the interpretation of the information collected, which makes the patient vulnerable to emotional expressions of anxiety about this information. ${ }^{2}$

Given the broad access to health information, what should be the physician's attitude in face of this new reality of numerable technological subsidies? The Code of Medical Ethics of the Brazilian Federal Council of Medicine, in its Chapter XIII, "Medical Advertising", in Article 144, says that the physician should not prescribe, consult or diagnose through mass communication. ${ }^{7}$ Thus, the doctor-patient relationship in the online scope imposes responsibilities and new challenges to these professionals.

Physicians' opinions about the impact of health information that is available online and in the mass media need to be better known in Brazil. In addition, it is recognized the real need to discuss the topic of the doctor-patient relationship in the information age, in order to improve communication between the medical professional and their client. In this perspective, the present study aims to analyse opinions and attitudes reported by medical specialists regarding online health information and their interference in the doctor-patient relationship.

\section{METHODS}

It refers to a cross-sectional analytical study developed between April 2016 and July 2017 in Recife, Pernambuco, Brazil. In this study, 183 specialist physicians who provide care at the outpatient clinics of Gynaecology and Obstetrics, Medical Clinic and subspecialties, Dermatology, General Surgery, Clinical Oncology, Oncology Surgery and Plastic Surgery at the Instituto de Medicina Integral Professor Fernando Figueira (IMIP) have received, personally, during intervals of their professional activities, a questionnaire prepared by the researchers based on the literature.

The sample of participating professionals was obtained from the consultation in the National Registry of Health Institutions (CNES). The respondents were selected at the time of collection, upon their availability, to respond to the questionnaire, since they were approached by the researchers at their workplace. Physicians who did not make themselves available to answer the questionnaire and to participate in the survey and those who were dismissed from their professional activities during the period of data collection were excluded.

Data collection was performed in two phases: the first corresponded to the semantic validation of the structured questionnaire with ten professionals who did not participate in the study, in order to assess the clarity and relevance of the questions and the adequacy of the response scale for possible corrections, prior to its application in the study. After semantic validation of the questionnaire, the second phase of the collection was performed, in which the volunteers answered the final questionnaire.

The questionnaire contained, in addition to information on the sociodemographic profile of the respondents, questions about the attitudes and opinions of physicians regarding health information on the Internet and other media. The last part of the questionnaire was a Likert-type scale with five options for answering the sentences (totally disagree, disagree, no opinion, agree and totally agree), on the same theme: the impact of online information on the doctor- patient relationship.

The questionnaire data were analysed descriptively by obtaining absolute and percentage frequencies for the categorical variables. For the age variables and variables of the part of the questionnaire with the Likert-type scale, there was the inferential analysis through the average Ranking statistics and 
standard deviation. In the calculation of the average Ranking, points 1 to 5 were considered for the answer options, with the number 1 corresponding to the "totally disagree" answer and number 5 corresponding to "totally agree". Also referring to the part of the questionnaire with the Likert scale, to compare the answers according to the medical specialties, the Kruskal-Wallis test was used. In the case of a significant difference with the Kruskal-Wallis test, the multiple comparisons tests (among specialty peers) of the test were used. For the calculation of statistically significant relationships in relation to the categorical variables, Pearson's Chi-square test or Fisher's Exact test was used when the condition for using the Chi-square test was not verified. The margin of error used in the statistical test decision was 5\%.

The data was entered in the Microsoft Office Excel spreadsheet and the program used to make the statistical calculations was the Statistical Package for the Social Sciences (SPSS) version 23.

The research project was analysed and approved by the Ethics Committee for Research with Human Beings of the Faculdade Pernambucana de Saúde, under number CAAE 56167516.6.0000.5569 and voucher number 044236/2016. All participants were informed about the research objectives and guided towards the confidentiality of the questionnaire responses. Participants were also informed that they could withdraw their participation in the survey at any time. After agreement with the Informed Consent Form (TCLE), the participants who declared that they were willing to answer the self-administered questionnaire did so. There are no conflicts of interest.

\section{RESULTS}

The total number of physicians participating in the survey was 183 and the socio-demographic profile of the respondents is detailed in Table 1. The age of the professionals surveyed ranged from 24 to 73 years, with an average of 38.29 and a standard deviation of 9.88 years old.

Regarding the opinions and attitudes reported by the respondents about the interference of online health information in the doctor-patient relationship, the data obtained are shown in Table 2. It was verified that, for the fixed margin of error (5\%), no significant associations between the specialties were registered, with none of the variables described in Table 2 ( $>>0.05)$.

Figure 1 shows the average Ranking and standard deviation of the answers of the sentences of the portion of the questionnaire with the Likert-type scale. When analysing physicians' responses to this part of the questionnaire by percentage calculations, it was found that $73.8 \%$ of respondents agree that online health information has positive effects for the general public. Among them, 91.2\% agreed that participation of patients in online forums made up of people with the same condition/disease can improve the patient's self-esteem and improve the doctor-patient relationship. For the sentence "Online health information can encourage patients to follow recommended treatments and seek medical professionals' instructions", a very significant percentage (91.2\%) agreed. About whether online information encourages patients who neglect their disease to take better care of themselves,

FIGURE 1 - Mean ranking of Likert scale sentences, presented in ascending order, of the physicians' answers in outpatient clinics of Gynaecology and Obstetrics, Medical Clinic and subspecialties, Dermatology, General Surgery, Clinical Oncology, Oncology Surgery and Plastic Surgery. Data collected at the Instituto de Medicina Integral Professor Fernando Figueira (IMIP) in Recife, Pernambuco, Brazil, between December 2016 and April 2017.
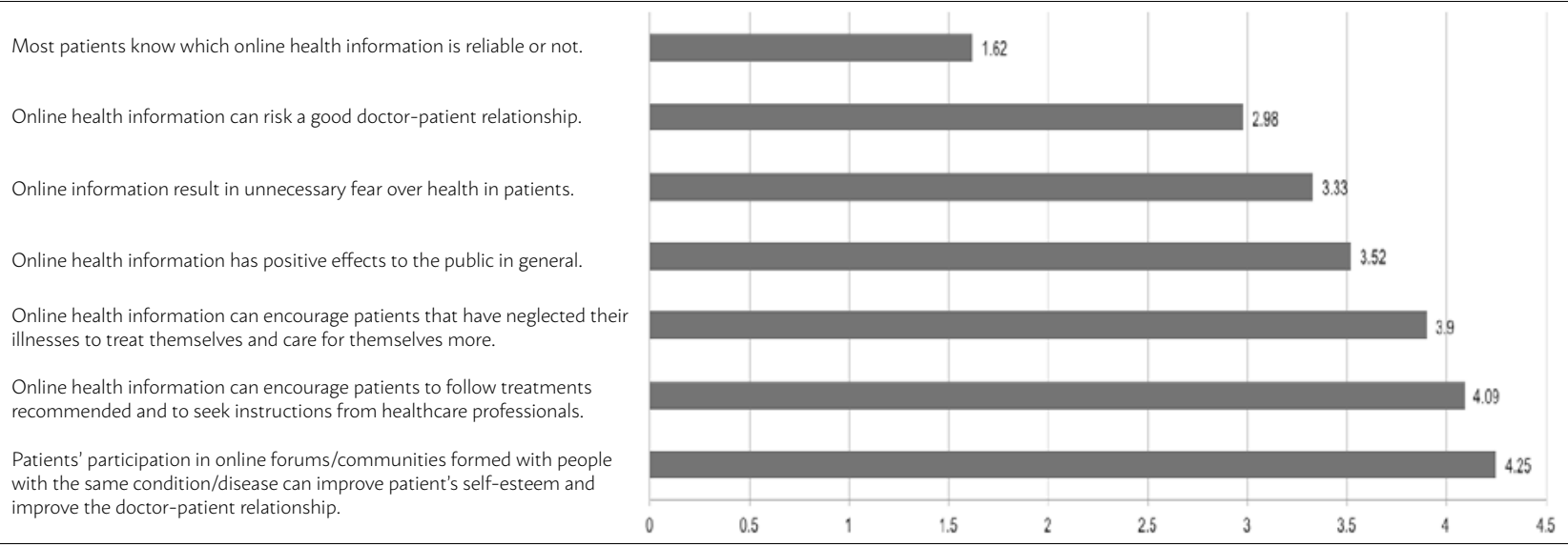
TABLE 1 - Sociodemographic profile of physicians from outpatient clinics of Gynaecology and Obstetrics, Medical Clinic and subspecialties, Dermatology, General Surgery, Clinical Oncology, Oncology Surgery and Plastic Surgery - Data collected at the Instituto de Medicina Integral Professor Fernando Figueira (IMIP) in Recife, Pernambuco, Brazil, between December 2016 and April 2017.

\begin{tabular}{l|l|l}
\hline Variable & $\mathbf{n}$ & $\%$ \\
\hline TOTAL & 183 & 100.0 \\
\hline
\end{tabular}

\begin{tabular}{l|l|l}
\hline Gender & & \\
\hline Male & 77 & 42.1 \\
\hline Female & 106 & 57.9 \\
\hline
\end{tabular}

\begin{tabular}{l|l|l}
\hline Age group (years) & & \\
\hline 24 to 39 & 120 & 65.6 \\
\hline 40 to 59 & 54 & 29.5 \\
\hline 60 to 73 & 9 & 4.9 \\
\hline
\end{tabular}

\begin{tabular}{l|l|l}
\hline Year of graduation in Medicine & & \\
\hline 1968 to 1999 & 55 & 30.1 \\
\hline 2000 to 2010 & 79 & 43.2 \\
\hline 2011 to 2016 & 49 & 26.8 \\
\hline
\end{tabular}

\begin{tabular}{l|l|l}
\hline Graduation institution & & \\
\hline Public & 159 & 86.9 \\
\hline Private & 24 & 13.1 \\
\hline
\end{tabular}

\begin{tabular}{l|l|l}
\hline Place of graduation & & \\
\hline Recife & 139 & 76.0 \\
\hline Outside Recife & 44 & 24.0 \\
\hline & & \\
\hline Specialty & & \\
\hline Gynaecology and Obstetrics & 51 & 27.9 \\
\hline Medical clinic & 70 & 38.3 \\
\hline Dermatology & 4 & 2.2 \\
\hline General surgery & 30 & 16.4 \\
\hline Clinical oncology & 18 & 9.8 \\
\hline Oncology surgery & 3 & 1.6 \\
\hline Plastic surgery & 7 & 3.8 \\
\hline
\end{tabular}

\begin{tabular}{l|l|l}
\hline Employment relationship & & \\
\hline Public outpatient clinic & 18 & 9.8 \\
\hline Private/public outpatient clinic & 40 & 21.9 \\
\hline Hospital sector & 1 & 0.5 \\
\hline Public outpatient clinic and hospital sector & 60 & 32.8 \\
\hline Private/public outpatient clinic and hospital sector & 64 & 35.0 \\
\hline
\end{tabular}

83.1\% agreed. Although most agree on the above sentences, $59.6 \%$ of physicians believe that this information results in unnecessary fears about the patients' health. In addition, 50.3\% agreed that this information online could "jeopardize the good doctor-patient relationship" and $89.1 \%$ of the respondents disagree with the sentence: "most patients know what health information online are reliable or not".
Comparing the average Ranking of the answers of the physicians from different specialties, a statistically significant difference $(p=0.032)$ was observed in relation to the sentence "Online health information results in unnecessary health fears on the part of the patients", so that for Gynaecology and Obstetrics physicians the value obtained was 3.57 ; for those of Clinical Oncology, 2.72; for those of Surgery 
TABLE 2 - Answers of physicians from outpatient clinics of Gynaecology and Obstetrics, Medical Clinic and subspecialties, Dermatology, General Surgery, Clinical Oncology, Oncology Surgery and Plastic Surgery about opinions about the impact of online health information on doctor-patient relationship - Data collected at the Instituto de Medicina Integral Professor Fernando Figueira (IMIP) in Recife, Pernambuco, Brazil, between December 2016 and April 2017.

\begin{tabular}{|c|c|c|}
\hline Variable & $\mathrm{n}$ & $\%$ \\
\hline TOTAL & 183 & 100.0 \\
\hline \multicolumn{3}{|c|}{$\begin{array}{l}\text { `Q1 - Before a patient who claims to have researched information about a particular disease on the internet and com- } \\
\text { ments on this information with you, questioning your behaviour or diagnostic hypotheses, you: }\end{array}$} \\
\hline - Feel that your authority has been questioned. & 1 & 0.5 \\
\hline - Try to explain to the patient the reasons for your hypotheses or conduct. & 181 & 98.9 \\
\hline - Indicate your diagnosis/conduct for considering it the best, but without explaining why. & - & - \\
\hline - That never happened to you, and you'd be in doubt about how to react. & 1 & 0.5 \\
\hline
\end{tabular}

\begin{tabular}{l|l|l}
\hline \multirow{2}{*}{$\begin{array}{l}\text { *Q2 - Do you indicate or have indicated websites or other media sources for better instruction of patients or when } \\
\text { requested by them? }\end{array}$} & \\
\hline- Yes. & 52.5 & 96 \\
\hline- No. & 87 & 47.5 \\
\hline
\end{tabular}

\begin{tabular}{|c|c|c|}
\hline $\begin{array}{l}{ }^{*} \mathrm{Q} 2 \mathrm{~A}-\text { If so, } \\
\text { illness?(1) }\end{array}$ & & \\
\hline - Rarely. & 23 & 12.6 \\
\hline - Eventually. & 61 & 33.3 \\
\hline - Frequently. & 12 & 6.6 \\
\hline
\end{tabular}

${ }^{*} \mathrm{Q} 2 \mathrm{~B}$ - If not, why have you never indicated to your patients websites or other reliable sources to instruct them about their illnesses (it is possible to choose more than one alternative)?(2)

- Patient's low instruction level 26

- No patient l've cared for has presented such demand. 35

- Most websites are not reliable.

- I need to research websites and other sources for patient information, as I do not know much about these sources. - Other.

\begin{tabular}{|l|l} 
& \\
\hline 26 & 29.9 \\
\hline 35 & 40.2 \\
\hline 21 & 24.1 \\
\hline 17 & 19.5 \\
\hline 11 & 12.6 \\
\hline
\end{tabular}

\begin{tabular}{|c|c|c|}
\hline $\begin{array}{l}\text { *Q3- Do you have a webpage on any soc } \\
\text { health information relating to your specia }\end{array}$ & & \\
\hline - Yes. & 24 & 13.1 \\
\hline - No and I'm not interested in having it. & 112 & 61.2 \\
\hline - No, but I intend to have it. & 47 & 25.7 \\
\hline
\end{tabular}

*Q4 - In a hypothetical situation, if a patient is interested in knowing more about their illness/health issue and asks you about which source(s) on the internet is (are) reliable and which is (are) in a language accessible to them, you:

- Say that you will provide the sources in the next appointment, because you need to research good sources.

- Already have sources in mind that meet the patient's needs.

- Know some sources for patient education, but say you can research more and provide others in the next appointment.

- Do not present research sources for not considering the Internet as a safe way of providing information.

- None of the above.

\begin{tabular}{|l|l}
\hline & \\
\hline 45 & 24.6 \\
\hline 49 & 26.8 \\
\hline 75 & 41.0 \\
\hline 10 & 5.5 \\
\hline 4 & 2.2 \\
\hline
\end{tabular}

\begin{tabular}{|c|c|c|}
\hline $\begin{array}{l}{ }^{*} \mathrm{Q} 5 \text { - In your opinion, the information accessed online and in social } \mathrm{m} \\
\text { treatment? }\end{array}$ & & \\
\hline - No. & 1 & 0.5 \\
\hline - Yes. It can positively change patients' attitudes. & 12 & 6.6 \\
\hline - Yes. It can negatively change patients' attitudes. & 8 & 4.4 \\
\hline - Yes. It can change both positively and negatively patients' attitudes. & 162 & 88.5 \\
\hline
\end{tabular}




\begin{tabular}{|c|c|c|}
\hline Variable & $\mathrm{n}$ & $\%$ \\
\hline \multicolumn{3}{|l|}{$\begin{array}{l}\text { *Q6 - Have you had any experience in which the patient reported that they changed aspects of the recommended treat- } \\
\text { ment after having seen information about the disease on the internet or other media? }\end{array}$} \\
\hline - Yes. & 108 & 59.0 \\
\hline - No. & 27 & 14.8 \\
\hline - No, but there was questioning about the recommended treatment. & 36 & 19.7 \\
\hline $\begin{array}{l}\text { - This never happened to me but l've heart accounts from colleagues who had a similar experi- } \\
\text { ence. }\end{array}$ & 12 & 6.6 \\
\hline \multicolumn{3}{|l|}{ ^Q7 - How do you assess the impact of online and media health information on the doctor-patient relationship? } \\
\hline - Positive impact. & 12 & 6.6 \\
\hline - Negative impact. & 10 & 5.5 \\
\hline - Both positive and negative impact. & 156 & 85.2 \\
\hline - I need to research more about the impact of this information, as I do not have any opinion about this. & 5 & 2.7 \\
\hline
\end{tabular}

(General, Oncology and Plastic), was 3.15, and for the Medical Clinic and Dermatology group it was 3.42.

\section{DISCUSSION}

The physicians' profile of the studied sample understands that before a questioning patient, the physician should make them understand the diagnosis and treatment, making the patient an active agent. In the study by Murray et al. ${ }^{8}$, a national study in the United States found that a minority of physicians feel challenged by patients who bring health information to the appointment, a finding similar to this study. In the city of Santos, São Paulo, Brazil, Coelho et al. ${ }^{9}$ found that the minority of physicians (4.76\%) surveyed reported extreme discomfort when confronted with data that the patient researched before or after the appointment. Stevenson et al. ${ }^{10}$ concluded that increasing patient activism in the search for information does not interrupt the existing balance of power and does not change roles (physician and patient) in the appointment; the online health information is complementary to the patient's care and, therefore, would support the therapeutic relationship. ${ }^{10}$

This research found that more than half of physicians indicate websites or sources of other media besides the internet for patient enlightenment. Similar results were found in a cross-sectional study conducted by Schwartz et al. ${ }^{11}$, which evaluated 92 physicians in the United States, noting that $63 \%$ of them reported having already suggested a specific website to their patients. Thus, a study in seven European countries solidifies the importance of online access to information, demonstrating a benefi- cial effect in investigating citizens' health-related internet use patterns and finding that it was twice as common to feel reassured after online use than experiencing feelings of anxiety. ${ }^{12}$ However, the practitioner should be familiar with the internet to better guide his/her patients about medical knowledge, since most are composed of lay people, and should be engaged more in the improvement of websites with health content available.

It is observed that a favourable assessment of online health information predominates among those surveyed as to its possible positive effects on the patients' condition in general. However, one can note medical uncertainty regarding patients' judgment about the information accessed as to its truthfulness, since about $89 \%$ of physicians agreed that most lay people do not know what online health information is reliable or not. Murray et al. ${ }^{8}$, still in the 2003 publication of the national study with US physicians, concluded that quality information accessed by patients has a beneficial effect, but misinformation has a detrimental effect. This effect could generate deleterious consequences to the patient insofar as they changes aspects related to their treatment.

Knowing the risks of misuse of online content, most health websites are an important market source in today's culture, as it is kept apart from any regulation or validation of the information it disseminates, thus allowing publication of scientific data with subjective impressions, possibly marked by resentment, exhibitionism or ideology propagation. ${ }^{13}$ Moretti et al. $^{14}$, in an interview with physicians from São Paulo, Brazil, observed that the interviewees gave great emphasis to the importance of public sector initiatives 
in the sense of qualifying health information that is made available on the Internet, and the Ministry of Health was the most mentioned agency among the entities that could be responsible for the certification of websites. This could minimize the damaging effect of misinformation about health on the internet.

Corroborating the importance of indicating appropriate websites, a survey, conducted in Australia based on patient perception, concluded that healthcare professionals were referred to as the most commonly selected option to help patients find reliable information on the internet. ${ }^{15,16}$ The Code of Medical Ethics, in its Chapter XIII, states that physicians may be allowed to participate in any mass media exclusively for the purpose of enlightening and educating society. ${ }^{5}$ In this way, the physician could be a reliable source of information for patients, which is positive for enhancing the patient's ability to appropriately decide on diagnostic and treatment processes, making the doctor-patient relationship more reliable and safe. Percentage of $13 \%$ of those surveyed in this study reported having an online webpage to publish health information intended for patients.

In this study, most of the respondents have had some experience in which the patient reported that changed aspects of the recommended treatment. In this regard, a study carried out in Canada noted that although health information on the internet has some effect on the process of agreement between patients and physicians, it is up to the practitioner to develop communication skills to convince the patient of his/her convictions through empathy.15 Thus, the physician should not fear this new and established tool, nor regard it as his competitor, and he/she must consider the patient's effort to find the information and discuss it with him/her. Certifying this idea, in a Spanish survey, $80.8 \%$ of patients believe that their physician would be willing to talk to them about the information found in the web.17

That said, this survey conducted in the city of Madrid, Spain found that the majority of Internet users commented on changes in health behaviour with their physician and among those who changed their way of thinking about health after searching online information, the majority also feel more interested in such issues. ${ }^{17}$ Thus, we can observe patients more committed to their health and therefore more participative in the decisions to be made, proving the finding in this study in which dominance is observed
(91.2 \%) of physicians agreeing that online health information can encourage patients to follow recommended treatments and seek the advice of medical professionals.

It was observed in this research that, among medical specialties, oncologists tend to disagree with the sentence "Online health information results in unnecessary patient fears about health", while other specialties tend to show "no opinion". In parallel with this result, a greater number of oncology patient surveys were found gaining support in forums/ communities for patient assistance. ${ }^{18-21}$ Thus, oncologists may have a more positive opinion regarding the search for online websites due to existing evidence. But further research needs to be carried out to explain this phenomenon.

It is also worth noting that the following assertions of the Likert scale - "Online health information has positive effects on the general public", "Online information results in unnecessary health fears for the patients" and "Online health information may jeopardize good doctor-patient relationship" - bring results that reveal a discrepancy in responses among respondents due to the numerical value observed when applying the standard deviation. The variation of responses between total agreement and total disagreement of reported opinions suggests a lack of consensus in the medical class consulted and/or little personal involvement with online publications in the healthcare area.

Among the limitations of the study, the difficulty of reaching the correct population and sample size among the medical specialties stands out, since the data obtained through the National Registry of Health Institutions did not match the reality present in the outpatient clinics of the collection place. It is important to emphasize that the research carried out was based on calculations made by the personal impression of the physicians, and does not necessarily reflect what happens in practice in relation to the attitude adopted by patients.

\section{CONCLUSION}

It is understood that access to health information on the internet is not without risk, such as insecurity and fears, both for patients and physicians. On the other hand, the promotion of benefits through the internet, such as the creation of instruments to cope with life situations and emotional relief, is already 
recognized as a positive effect for certain patients. It should be understood the cognitive aspect of the patient as determinant for interpretations of the online health information and the medical ability of critical assessment for the discernment of the impact on the patient of the information found by them, in order to determine if it is relevant to the condition of the patient and whether it is based on the best evidence available, since patients started to have an active voice in the definition and choice of treatments through the principle of autonomy, a right guaranteed by the Code of Medical Ethics. Thus, recognizing the information age as a social advance is necessary, weighing positive and negative aspects, to continue the endless process of improving communication and the doctor-patient relationship.

\section{RESUMO}

OBJETIVOS: Analisar opiniões e atitudes relatadas por médicos especialistas diante das informações de saúde on-line e suas interferências na relação médico-paciente. Métodos: Estudo transversal desenvolvido entre 2016 e 2017 em Recife, Pernambuco, Brasil, que utilizou um questionário presencialmente em uma população de 183 médicos especialistas do Instituto de Medicina Integral Prof. Fernando Figueira. Os resultados foram analisados por meio do Statistical Package for the Social Sciences. Obtida aprovação do Comitê de Ética sob o número de comprovante 121004/2016. Resultados: Na opinião de 85,2\% dos médicos, as informações on-line sobre saúde têm tanto impacto positivo quanto negativo na relação médico-paciente. Diante de um paciente questionador, que diz ter pesquisado informações na rede, 98,9\% dos médicos fazem com que o usuário entenda as razões sobre seu diagnóstico e tratamento; $59 \%$ já tiveram paciente que modificou o tratamento recomendado por ter visto informações na internet; 73,8\% concordam que as informações on-line sobre saúde têm efeitos positivos para o público em geral, mas 89,1\% opinam que a maioria dos pacientes não sabe quais informações sobre saúde on-line são confiáveis.

CONCLUSÃo: Os médicos pesquisados veem as informações on-line sobre saúde de forma positiva, mas percebem que é necessário ter cautela quanto às repercussões destas sobre o tratamento dos pacientes. Há preocupação quanto à acurácia dessas informações, cabendo ao médico e às instituições de saúde instruir os pacientes quanto às fontes de qualidade e que estejam acessíveis ao entendimento de leigos, visto que os pacientes passaram a ter voz ativa por meio da garantia do princípio ético da autonomia.

PALAVRAS-CHAVE: Internet. Relações médico-paciente. Papel do médico. Participação do paciente.

\section{REFERENCES}

1. Goldin JR, Franciscone CF. Modelos de relação médico-paciente. [Citado 16 maio 2017]. Disponível em: http://www.ufrgs.br/bioetica/relacao.htm.

2. Briet JP, Hageman MG, Blok R, Ring D. When do patients with hand illness seek online health consultations and what do they ask? Clin Orthop Relat Res. 2014;472(4):1246-50.

3. Kurup V, Considine A, Hersey D, Dai F, Senior A, Silverman DG, et al. Role of the Internet as an information resource for surgical patients: a survey of 877 patients. Br J Anaesth. 2013;110(1):54-8.

4. Liszka HA, Steyer TE, Hueston WJ. Virtual medical care: how are our patients using online health information? I Community Health. 2006;31(5):368-78.

5. Rose S, Bruce J, Maffulli N. Accessing the Internet for patient information about orthopedics. JAMA. 1998;280(15):1309.

6. Rocha BV, Gazim CC, Pasetto CV, Simões JC. Relação médico-paciente. Rev Med Res. 2011;13(2):114-8.

7. Conselho Federal de Medicina - CFM. Código de ética médica: Resolução CFM no 1931, de 17 de setembro de 2009 (versão de bolso). 2010. [Citado 16 maio 2017]. Disponível em: http://www.cremers.org.br/pdf/codigodeetica/codigo_etica.pdf.

8. Murray E, Lo B, Pollack L, Donelan K, Catania J, Lee K, et al. The impact of health information on the Internet on health care and the physician-patient relationship: national U.S. survey among 1.050 U.S. physicians. J Med Internet Res. 2003;5(3):e17.

9. Coelho EQ, Coelho AQ, Cardoso JED. Informações médicas na internet afetam a relação médico-paciente? Rev Bioét. 2013; 21(1):142-9.

10. Stevenson FA, Kerr C, Murray E, Nazareth I. Information from the Internet and the doctor-patient relationship: the patient perspective: a qualitative study. BMC Fam Pract. 2007;8:47.

11. Schwartz KL, Roe T, Northrup J, Meza J, Seifeldin R, Neale A. Family medicine patients' use of the Internet for health information: a MetroNet study. J Am Board Fam. 2006;19(1):39-45.
12. Andreassen HK, Bujnowska-Fedak MM, Chronaki CE, Dumitru RC, Pudule I, Santana S, et al. European citizens' use of E-health services: a study of seven countries. BMC Public Health. 2007;7:53.

13. Schmidt E, Viana SMSA, Andrade EBM, Fernandes MD, Rezende SPI, Reis PVS, et al. A inclusão da internet na relação médico-paciente: apenas prós? Rev Bras Clin Med. 2013;11(4).

14. Moretti FA, Oliveira VE, Silva EMK. Acesso a informações de saúde na internet: uma questão de saúde pública? Rev Assoc Med Bras. 2012;58(6):650-8.

15. Laugesen J, Hassanein $K$, Yuan $Y$. The impact of Internet health information on patient compliance: a research model and an empirical study. J Med Internet Res. 2015;17(6):e143.

16. Lee K, Hoti K, Hughes ], Emmerton L. Dr Google is here to stay but health care professionals are still valued: an analysis of health care consumers' Internet navigation support preferences. J Med Internet Res. 2017;19(6):e210.

17. Marin-Torres V, Valverde Aliaga J, Sánchez Miró I, Sáenz Del Castillo Vicente MI, Polentinos-Castro E, Garrido Barral A. Internet as an information source for health in primary care patients and its influence on the physician-patient relationship. Aten Primaria. 2013;45(1):46-53.

18. Chiu YC. Probing, impelling, but not offending doctors: the role of the internet as an information source for patients' interactions with doctors. Qual Health Res. 2011;21(12):1658-66.

19. Broom A, Tovey P. The role of the Internet in cancer patients' engagement with complementary and alternative treatments. Health (London). 2008;12(2):139-55.

20. Bylund CL, Gueguen JA, D'Agostino TA, Imes RS, Sonet E. Cancer patients' decisions about discussing Internet information with their doctors. Psychooncology. 2009;18(11):1139-46.

21. Chen $X$, Siu LL. Impact of the media and the Internet on oncology: survey of cancer patients and oncologists in Canada. J Clin Oncol. 2001;19(23):4291-7. 